\title{
Study on commuter travel of urban workers_-Analysis of coordination between ground bus and rail transit in Beijing
}

\author{
Qi TianPei ${ }^{1}$, Peng ZhaoQi ${ }^{1}$ \\ ${ }^{1}$ Department of Labor Economics, BJTU, No.3 Shangyuan Village, Haidian District, Beijing
}

\begin{abstract}
At present, with the advancement of China's urbanization construction process, China's urbanization rate has gradually increased in recent years, and the population in the suburbs and surrounding towns and rural areas continue to pour into large cities, which inevitably leads to a series of social problems in the process of China's urban economic development. In the process of population gathering in large cities, traffic problems have a great impact on urban workers. With the increase of urban population and the rising stock of private cars, the efficiency of ground transportation continues to decline; the population aggregation in big cities, the poor travel experience of public transport system in the morning and evening rush hours on weekdays, and the long commuting time and distance of workers restrict the long-term development of large cities in China to a certain extent. This paper studies the coordination between ground public transport and rail transit in Beijing with reference to the coordination of the development of ground public transport and rail transit. Finally, based on these problems, this paper puts forward some suggestions for the long-term coordinated development of public transport in Beijing.
\end{abstract}

\section{Research background}

Through the analysis and investigation of the traffic situation in Beijing, we can draw a conclusion that the existing urban road network can no longer support the increasing urban population, and it is far from meeting the growing diversified travel needs of workers only by means of new urban roads and increasing workers' personal daily travel (i.e. private car travel), moreover, it cannot meet the travel needs of workers to arrive at the destination in time on weekdays, and cannot fundamentally solve the problem of urban ground traffic congestion. Therefore, in addition to solving the "old and difficult" problem of urban traffic development from the perspective of road expansion, vigorously developing urban public transport has also become the preferred urban planning scheme for major cities. By means of "ground bus + urban rail transit", coordinated development can solve the daily travel problems of residents and relieve the pressure of urban roads.

As early as the end of 2012, the State Council has issued the "guidance" document notice, which has noticed the problems of urban public transport in big cities. Its purpose is to promote the construction of public transport in big cities and improve the current situation of urban traffic. The transportation characteristics of urban rail transit are large traffic volume, guaranteed time, comfortable ride process, etc., which can meet the rapid travel needs of workers from "point to point" on weekdays. It is widely recognized by workers, and most workers choose urban rail transit as the preferred means of transportation for long-distance commuting. To promote the rapid development of urban rail transit and effectively play its backbone role in urban public transport has become the development trend of urban public passenger transport system in the future. ${ }^{[1][2]}$

\section{Analysis on the coordination of urban ground bus and rail transit development}

\subsection{Connotation of public transport coordination}

The coordination of public transport mainly includes the following specific issues: whether the transfer distance between different modes of transportation meets the psychological expectations of passengers, whether the coverage of urban ground bus network can meet the travel needs of most passengers in various regions, and whether the specified departure interval of urban rail transit network is reasonable. Such problems in urban construction and urban planning development can be classified as urban public transport operation coordination problems, which can be analyzed from the aspects of urban public transport operation coordination. ${ }^{[3][4]}$

The main analysis framework of this paper is based on the daily operation of urban public transit and rail transit, and the transfer coordination between them. It also elaborates on the construction and operation of urban rail transit system and the planning and reasonable operation of urban public transit network.

\footnotetext{
" Corresponding author: qtp544231671@163.com
} 


\subsection{Problems existing in the construction of urban ground bus and rail transit}

There is no doubt that urban development cannot be separated from the construction of urban public transport, but there are still many problems in the construction of ground public transport and rail transit in many cities in China. From the perspective of rail transit, the construction of some cities in China is overheated. At present, most of the second-tier cities and even some of the third-tier cities require the planning and construction of rail transit network. Part of the demand is caused by the rapid development of the city, while a considerable part of the engineering construction is due to the pursuit of political achievements and other factors by city managers during their term of office. They blindly require the construction of a large number of urban rail transit networks, which is completely divorced from reality, the daily traffic demand in the city is not fully considered and calculated. Secondly, the standard structure of China's urban rail transit construction is unreasonable. From the reality of Beijing, Beijing is still vigorously promoting the construction of subway, light rail and other high-volume and high-cost modes of transportation, while tram and other low-cost modes of rail transportation have not yet become the mainstream of public transportation. ${ }^{[5]}$

From the perspective of ground bus, although its construction cost is low, the operation coverage area of the city is wide, and Beijing has set up bus lanes since 2011, but due to the low efficiency of implementation of various policies and measures, the overall congestion of urban ground traffic, the development of the ground bus system is slow, and because Beijing ground bus system does not follow up the construction process of its rail transit in time, it cannot form a good transfer system between the urban rail transit and the urban rail transit, which leads to the poor daily commute travel experience of the urban workers.

\section{Analysis on the problem of commuters in Beijing}

\subsection{Analysis of commuting distance and commuting time between ground bus and workers in Beijing}

According to the average travel distance of residents using ground bus in Beijing from 2011 to 2018, the travel distance of most workers was about $10 \mathrm{~km}$, which dropped to $7.3 \mathrm{~km}$ in 2015 , while the travel distance of urban workers was about $10 \mathrm{~km}-11 \mathrm{~km}$ from 2016 to 2018 . The standard for urban comprehensive transportation system planning (here in after referred to as the standard) clearly states that the travel distance of residents in cities with more than 5 million urban population in China should be within $9 \mathrm{~km}$, and it can be appropriately increased in mega cities with more than 10 million urban population. Therefore, only from the perspective of the average travel distance of workers in Beijing using the ground bus, this travel distance basically meets the relevant standards.

The average travel speed of workers using ground bus in Beijing decreased slightly from 2011 to 2015, reaching $7.1 \mathrm{~km} / \mathrm{h}$, the minimum value from 2011 to 2018 . The average travel speed of workers using ground bus in Beijing remained between $9 \mathrm{~km} / \mathrm{h}$ and $10 \mathrm{~km} / \mathrm{h}$ from 2016 to 2018, while the relevant regulations in China showed that the ground bus transportation speed of urban trunk lines was not less than $20 \mathrm{~km} / \mathrm{h}$, the transportation speed of the general line is not less than $15 \mathrm{~km} / \mathrm{h}$, while the travel speed of Beijing workers using urban ground bus is obviously far behind the standard.

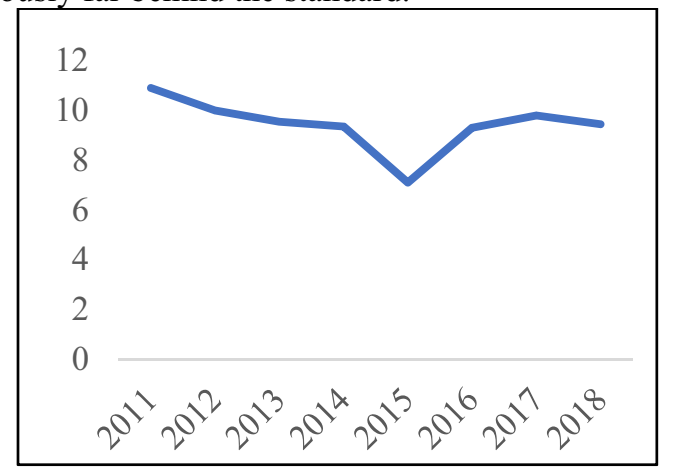

Fig. 1. Average travel speed of ground bus in Beijing ${ }^{[7]}$

The average travel time of Beijing workers using ground public transport has been fluctuating since 2011, and it is stable at about 66 minutes from 2016 to 2018 . Similarly, according to China's "standard", the commuting time of public transport should be controlled within 1 hour in cities with a planned population of more than 5 million. There is still room for improvement in Beijing's ground bus system. ${ }^{[6]}$

\subsection{Analysis of commuting distance and commuting time between rail transit and workers in Beijing}

From the data of average travel distance of Beijing Workers in rail transit, it can be seen that the daily commute distance of workers is more than $10 \mathrm{~km}$, which only decreased slightly in 2015 , and the distance between 2016 and 2018 is about $18 \mathrm{~km}$. From the side, it can be seen that the distribution of the office and residence in Beijing is unreasonable, and the daily commute distance of residents is too far. Similarly, according to the provisions of the standard, the average travel distance of residents in megacities with a planned population of more than 5 million should not exceed $9 \mathrm{~km}$. The standard of travel distance can be appropriately improved for megacities with more than 10 million people.

However, from the data of Beijing, it can be seen that the average travel distance of Beijing Workers in rail transit is twice that of the standard, which is closely related to the rapid development of urban rail transit in recent years. Since the urban rail transit network planning is more reasonable and more lines are opened, the residents who originally live in the surrounding areas of Beijing will use rail transit more in their working days. Therefore, the average travel distance of urban workers in the city will increase from 2016 to 2018.

Similarly, by analyzing the average travel speed of Beijing Workers in rail transit, after 2011, the operation 
speed of Beijing rail transit has been declining, which has been reduced to the lowest point of $11.6 \mathrm{~km} / \mathrm{h}$ in 2015 , and has been stable at about $15 \mathrm{~km} / \mathrm{h}$ in the last three years. According to the regulations of the subway operation speed standard in China, the subway speed should not be lower than $35 \mathrm{~km} / \mathrm{h}$, therefore, there is still a great room for the improvement of the speed of the rail transit in Beijing. ${ }^{[6]}$

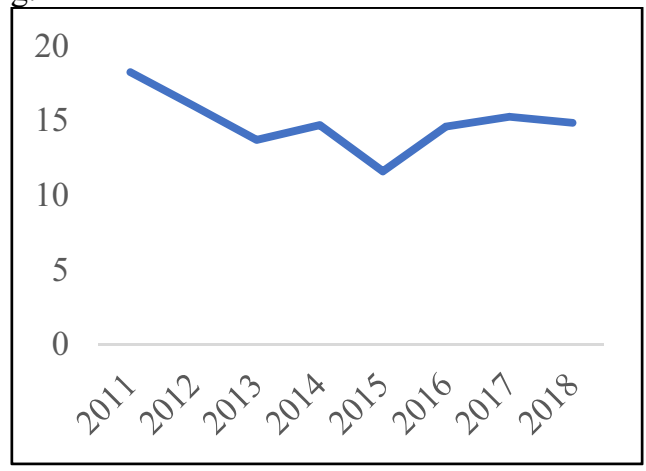

Fig. 2. Average travel speed of Beijing Railway ${ }^{[7]}$

\section{Conclusion and the Policy suggestion}

\subsection{Promote the synchronous matching of ground public transportation and rail transit construction}

In the construction of public transport in Beijing, in the past a long time, the construction of rail transit has been placed in the main position. More resources have been inclined to the development and construction of rail transit. The development and construction of ground public transport is placed in a secondary position, lagging behind the development of rail transit, and the public transport system in the city is not complete, it has affected the healthy development of urban public transport. Therefore, in the future development of urban public transport, the following measures can be taken:

(1) Parallel planning and construction of rail transit and ground bus

The government should carry out the preliminary feasibility study and preliminary design of the new rail transit lines in the future, organize the investigation and implementation of the ground bus supporting planning, fully consider the nature of land use along the rail transit lines, the travel of workers in working days and other issues, and clarify the connection mode and demand, facility scale, setting requirements and supporting schemes of each station along the rail transit lines. To provide the basis and support for the follow-up actual construction, try to avoid the problems of insufficient planning and thoughtless consideration;

(2) Adjust the connection line of ground bus

Secondly, the existing ground bus operation line should be adjusted accordingly. The long line running along the same line with rail transit should be adjusted to avoid the inefficient operation of ground public transport. The operation line of ground bus should be adjusted to the form of vertical or oblique intersection with the rail transit operation line as far as possible, so as to improve the operation efficiency of ground bus and give full play to the function of ground bus to connect and transport passenger flow of rail transit.

\subsection{Improve and implement the linkage mechanism between ground bus and rail transit}

Beijing Rail Transit and ground bus have different degrees of uncoordinated operation time and unmatched passenger transport capacity. To solve this problem, it is also an important measure to improve and implement the linkage mechanism between ground bus and rail transit.

(1) Speed up the information construction to provide technical support for the linkage mechanism of ground bus and rail transit

In order to improve the service and management level of urban public transport system, create a good urban traffic environment, and strengthen the information construction of urban public transport system, it is also one of the important measures. Information public transportation system includes operation command and dispatching system, passenger information service system, vehicle unit system, etc. The operation linkage between ground bus and rail transit, as well as the realization of the dynamic integration of fare adjustment and other initiatives, are inseparable from the information-based public transport system.

From the perspective of the construction of public transport system operation end, on the one hand, it is necessary to monitor the real-time traffic volume, capacity and departure time of ground public transport and rail transit through the information-based public transport system, timely allocate idle transport resources to the areas where transfer and connection are temporarily difficult, so as to avoid the problem of large area capacity mismatch along the rail transit transfer station;

From the perspective of passenger end construction, public transport operation departments need to provide real-time rail transit and ground bus operation information for the public through information platform, such as train arrival time, passenger full load rate and other issues, so that passengers can better plan their journey and get better travel experience.

(2) Improve the operation linkage mechanism of ground bus and rail transit

First of all, the first and last bus operating at the ground bus and rail transit transfer station should be connected. As mentioned above, the last bus time of the three rail transit lines at Xizhimen Station is after 22:30, while the night ground bus starts to operate around 23:00-23:30, and the connection of conventional ground bus stops around 22:00. Although the operation of public transport system needs to consider the operation cost and passenger capacity, from the perspective of passenger travel, in special periods such as weekends and holidays, the operation time of ground bus can be adjusted to connect with the operation time of rail transit, so as to meet the travel demand of late returning passengers;

At the same time, the passenger volume of ground bus and rail transit should be compatible. In the capacity arrangement of public transport, we should establish a 
good and smooth communication and coordination mechanism and information sharing mechanism, and a comprehensive scheduling mechanism between ground bus and rail transit, so as to realize the comprehensive coordination of real-time traffic volume and capacity between the two transport modes. For example, in the morning and evening rush hours, a large number of commuters gather in CBD business circles such as Xidan subway station and international trade station in a short period of time. It is necessary to increase the number of ground bus connections or shorten the departure interval during this period, allocate more ground bus resources, and quickly transport the passengers concentrated in densely populated areas such as office and residential areas to the travel destination, reduce the subway entrance and exit, bus stops around the queue congestion.

\section{Reference}

1. Kaufmann V, Sager F. The coordination of local policies for urban development and public transportation in four Swiss cities Journal of Urban Affairs 28, 353-374. (2006)
2. Brunner H, Hirz M, Hirschberg W, et al. Evaluation of various means of transport for urban areas. Energy, Sustainability and Society 8, 9 (2018)

3. Baum-Snow N, Kahn M E. The effects of new public projects to expand urban rail transit. Journal of Public Economics, 77, 241-263 (2000)

4. Vishwanath A, Gan H S, Kalyanaraman S, et al. Personalised Public Transportation: A New Mobility Model for Urban and Suburban Transportation, IEEE International Conference on Intelligent Transportation Systems. 0.

5. Deng Yuanhui, Ou Guoli, Xing Husong. Diversified supply of Urban Rail Transit under network form stratification, 20, 106-111(2013)

6. Zhao Hui, Yang Jun, Liu Changping, Study on the characteristics of job residence distribution and commuting spatial organization of residents along the railway line -- a case study of Beijing, 31, 14451451(2011)

7. Beijing Transportation Development Research Institute 